\title{
Development of heat treatment modes for a two- phase titanium alloy to form regulated structure and properties complex
}

\author{
Svetlana Skvortsova ${ }^{1, *}$, Galina Gurtovaya ${ }^{1}$, Maria Afonina $^{1}$, Natalya Ruchina ${ }^{1}$ and \\ Gulnara Zaynetdinova ${ }^{1}$
}

${ }^{1}$ MAI, 125993, 4 Volokolamskoe shosse, Moscow, Russia

\begin{abstract}
The article shows the possibility of creating structure of the same type and, accordingly, a close level of properties in hot-rolled semifinished products of the VST2K alloy with different chemical composition by means of heat treatment.
\end{abstract}

\section{Introduction}

Due to the unique combination of properties (high specific strength, corrosion resistance, and biological inertness) titanium alloys are widely used in various fields of aircraft and machine building, shipbuilding, and medicine. One of the most common titanium-based alloys has been the VT6 (Ti-6Al-4V) for more than half a century. The same alloy is one of the main materials for manufacturing implantable medical devices [1].

The production of titanium-based alloys is very expensive due to the need for special casting methods and poor machinability [2]. Therefore, manufacturers are always faced with the task of reducing the cost of ingots and semi-finished products. There are several ways to solve this problem. For example, improving production technology, creating economically alloyed alloys, and alloys with improved machining, etc. [3].

One of the ways to reduce the cost of titanium alloys production is to involve secondary raw materials in the production. It is the way that the creators of the VST2K alloy followed [4]. This structural alloy is close to the VT6 alloy (Ti-6Al-4V) by strength properties in the annealed state, while the proportion of waste used in its smelting reaches $50 \%$. Owing to involvement of titanium wastes with different multicomponent chemical compositions the permissible contents of $\beta$-stabilizing elements, such as $\mathrm{Mo}$ and $\mathrm{Cr}$, as well as $\mathrm{Ni}$ and $\mathrm{Si}$, are expanded in the VST2K alloy. Due to the unpredictable combination of waste different melts of the alloy can have very differing chemical compositions, and, accordingly, the structure and properties of the semi-finished products obtained from them will be different.

Therefore, the task was set to evaluate the possibility of developing heat treatment modes that ensure the formation of structure of the same type in semi-finished products of the VST2K alloy with different chemical compositions and, accordingly, obtainment of approximately the same level of properties.

\footnotetext{
* Corresponding author: skvorcovasv@mail.ru
} 


\section{Materials and procedures}

The studies were carried out on samples cut from hot-rolled plates of the VST2K titanium alloy obtained by industrial technology. The chemical composition of the studied plates is given in Table 1. Also table 1 shows the structural molybdenum equivalent $\left([\mathrm{Mo}]_{\mathrm{eq}}\right)$ calculated by the formula: $[\mathrm{Mo}]_{\mathrm{eq}}=[\mathrm{Mo}]+0.2[\mathrm{Ta}]+0.28[\mathrm{Nb}]+0.4[\mathrm{~W}]+0.67[\mathrm{~V}]+$ $1.25[\mathrm{Cr}]+1.25[\mathrm{Ni}]+1.7[\mathrm{Mn}]+1.7[\mathrm{Co}]+2.5[\mathrm{Fe}] \quad[5,6]$.

Table 1. Chemical composition of the investigated titanium alloys

\begin{tabular}{|c|c|c|c|c|c|c|c|c|c|c|}
\hline \multirow{2}{*}{\multicolumn{2}{|c|}{ Alloy }} & \multicolumn{5}{|c|}{ Alloying elements*, wt. \% } & \multicolumn{3}{|c|}{ Impurities, wt. \% } & \multirow[t]{2}{*}{$\begin{array}{c}{[\mathrm{Mo}]_{\mathrm{e}}} \\
\mathrm{q}\end{array}$} \\
\hline & & $\mathrm{Al}$ & V & $\mathrm{Cr}$ & $\mathrm{Fe}$ & Mo & $\mathrm{O}$ & $\mathrm{N}$ & C & \\
\hline \multirow{3}{*}{$\begin{array}{l}\text { VST2K } \\
\text { Composi- } \\
\text { tion \# }\end{array}$} & 1 & 5.67 & 4.22 & 0.11 & 0.46 & 0.15 & 0.1 & 0.016 & 0,015 & 4.27 \\
\hline & 2 & 5,68 & 4,28 & 0,45 & 0,48 & 0,81 & 0,1 & 0,021 & 0,02 & 5.44 \\
\hline & 3 & 5,68 & 4,27 & 1,49 & 0,51 & 0,80 & 0,1 & 0,015 & 0,023 & 6.8 \\
\hline
\end{tabular}

* except titanium

Preparation of samples for metallographic analysis was carried out according to the standard methods [7]. Microstructure was studied using the Axio Observer A1m optic microscope (magnification is up to 1000 times) and the Image Expert Pro3 digital software intended for acquisition and analysis of the images. Hardness was measured according to the Rockwell method in HRC scale using the BUEHLER Macromet 5100T device by a diamond cone with a vertex angle of $120^{\circ}$ and the load of $1500 \mathrm{~N}$.

\section{Results and discussion}

Metallographic studies of the $40 \mathrm{~mm}$-thick hot-rolled plates of the VST2K alloy showed that the structure of the plate with composition 1 is quite homogenous in thickness and represented by coarse primary $\alpha$ particles (in the amount of about $45 \%)$ and $(\alpha+\beta)$ twophase mixture located among them with lamellar secondary particles of $\alpha$ phase formed out of $\beta$ phase during cooling of the semi-finished product from rolling temperature to room temperature (Fig. 1a).

In the plate of composition 2 the size and number of primary $\alpha$ particles is smaller than in the alloy of composition 1 (about 35\%), and the fraction of lamellar precipitates of the secondary $\alpha$ phase is correspondingly higher, and its dispersion is observed (Fig. 1b). The structure of the plate with composition 3 differs significantly from the first two plates: it is characterized by a non-uniform particle size of the primary $\alpha$ phase with the volume fraction of no more than $20 \%$, and the secondary $\alpha$-phase is represented by thin dispersed lamellar particles. In addition, the structure is not well processed as evidenced by the presence in some places of the $\alpha$-fringe along the boundaries of the initial $\beta$-grains (Fig. 1c). Differences in structure are primarily associated with the chemical composition of the alloys. With an increase of $\beta$-stabilizers content a gradual decrease in both the amount of the primary $\alpha$-phase and the size of the secondary $\alpha$-phase is observed (Fig. 1). Differences in structure, especially in the amount and dispersion degree of the secondary $\alpha$-phase, result in different hardness of the semi-finished products in the initial state which varies from 32 HRC units for composition 1 to 38 HRC units for composition 3. Such a difference in the hardness of the semi-finished products will give a significant difference in mechanical properties. 


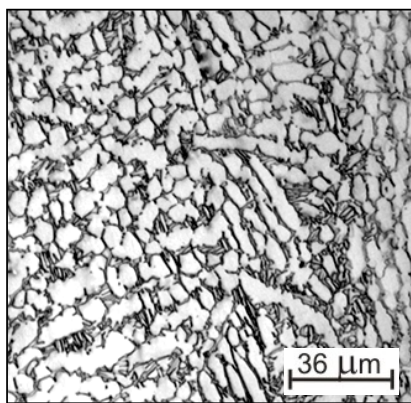

(a)

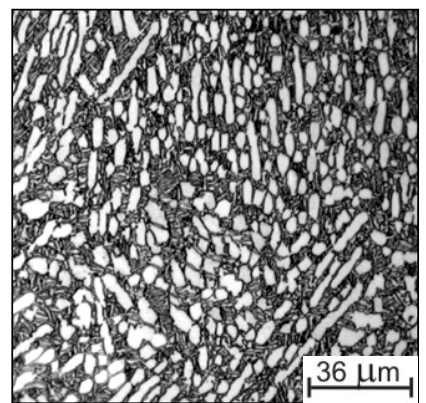

(b)

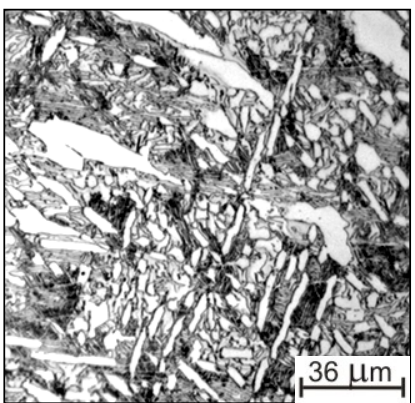

(c)

Fig. 1. Microstructure of the VST2K alloy plates with compositions 1 (a), 2 (b) and 3 (c) in hot-rolled state.

The difference in the chemical composition of the different melts of the alloy also determines the difference in the temperature of polymorphic $\alpha \rightarrow \beta$ transformation. Therefore, this temperature was determined by trial quenching method and corresponded to $990^{\circ} \mathrm{C}$ for composition $1,980^{\circ} \mathrm{C}$ for composition 2 and $970{ }^{\circ} \mathrm{C}$ for composition 3 .

The structure of the semi-finished products and, accordingly, their properties is needed to be approximately the same to make it possible to use them in the production of, for example, the stems of hip joint prostheses. Therefore, at the first stage of the work conventional annealing mode was used to transform the structure which included heating up to the temperature of $130{ }^{\circ} \mathrm{C}$ below the polymorphic transformation temperature (PTT, $\mathrm{Ac}_{3}$ ) followed by air cooling.

Figure 2 shows the structures of the samples with compositions 1,2 , and 3 in the annealed state. The annealing temperature was $860{ }^{\circ} \mathrm{C}$, $850{ }^{\circ} \mathrm{C}$, and $840{ }^{\circ} \mathrm{C}$, respectively, the holding time was 1 hour, and cooling to room temperature was carried out in air. It was determined that after conventional annealing structures with different volume fractions and particle sizes of the primary $\alpha$ phase as well as different dispersion degree of the secondary $\alpha$ phase are formed in samples of the VST2K alloy with different compositions (Fig. 2).

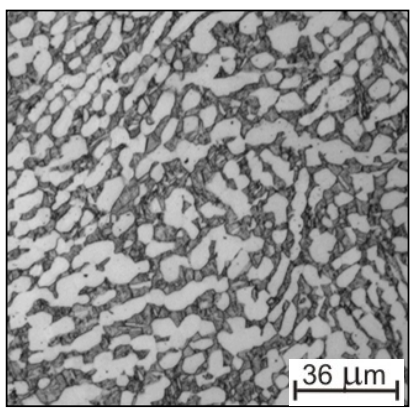

(a)

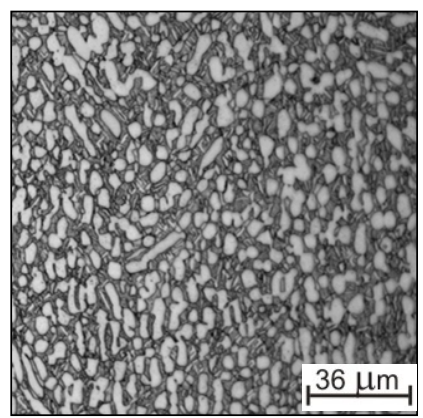

(b)

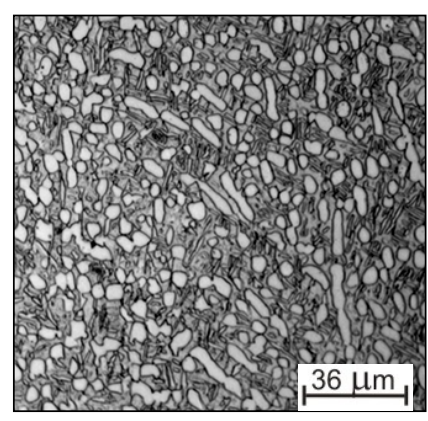

(c)

Fig. 2. Structure of the VST2K alloy with compositions 1 (a), 2 (b) and 3 (c) after annealing at the temperatures of $860^{\circ} \mathrm{C} \mathrm{(a),} 850^{\circ} \mathrm{C}$ (b) and $840^{\circ} \mathrm{C}$ (c) during 1 hour and air cooling

The number and particle size of the primary $\alpha$ phase depends on the chemical composition of the alloy (Table 2). In the annealed state the volume fraction of primary $\alpha$ phase particles in the alloy of composition 1 was about $50 \%$, composition $2-35 \%$, and composition $3-$ $30 \%$. In addition, with an increase in the molybdenum equivalent of the alloy the longitudinal size of the primary $\alpha$ phase plates $\left(a_{\alpha^{I}}\right)$ decreases while the transverse particle size (thickness) $\left(b_{\alpha^{I}}\right)$ remains almost unchanged (Table 2$)$. 
Table 2. Parameters of structure and hardness of the VST2K alloy samples after annealing at the temperature of $\left(\mathrm{PTT}-130^{\circ} \mathrm{C}\right)$ followed by air cooling

\begin{tabular}{|c|c|c|c|c|c|}
\hline $\begin{array}{c}\text { Composition } \\
\text { of the alloy }\end{array}$ & $\begin{array}{c}\mathrm{Ac}_{3}, \\
{ }^{\circ} \mathrm{C}\end{array}$ & $\begin{array}{c}\text { Annealing temperature, } \\
{ }^{\circ} \mathrm{C}\end{array}$ & $\begin{array}{c}\mathrm{Q} \alpha^{\mathrm{I}}, \\
\%\end{array}$ & $\begin{array}{c}a_{\alpha^{I}} / b_{\alpha^{I}}, \\
\mu \mathrm{m}\end{array}$ & HRC \\
\hline 1 & 990 & 860 & 50 & $7.1 / 2.2$ & 37 \\
\hline 2 & 980 & 850 & 35 & $4.6 / 1.8$ & 39 \\
\hline 3 & 970 & 840 & 30 & $4.1 / 1.6$ & 42.5 \\
\hline
\end{tabular}

The hardness after annealing was 37 HRC units for the samples of composition 1, 39 HRC units for those of composition 2 and 42.5 HRC units for composition 3 (Table 2). Such a difference in hardness of the samples of different melts after annealing and air cooling is due to the difference in the chemical composition of the alloy, i.e. the degree of solid solution hardening of the phases, as well as the structural factor.

Thus, conventional annealing mode does not lead to the desired result. To determine the heating temperature which ensures the formation of a structure with an approximately equal amount of the primary $\alpha$ phase in the VST2K alloy of different chemical composition, the samples were heated in the temperature range of $940-840{ }^{\circ} \mathrm{C}$ and cooled in water and in air. It was found that for three different alloy compositions approximately the same amount of the primary $\alpha$ phase of $30-35 \%$ is fixed after heating to the temperatures of $940{ }^{\circ} \mathrm{C}$ (composition 1), $920{ }^{\circ} \mathrm{C}$ (composition 2) and $880{ }^{\circ} \mathrm{C}$ (composition 3).

However, despite the similar amount of the primary $\alpha$ phase in all three melts, after annealing at selected temperatures and air cooling a large difference in hardness of the samples of different compositions remains (Table 3). This, apparently, is explained by the difference in the size and morphology of $\alpha$ phase particles, both primary and secondary, which are precipitated upon cooling to room temperature. In addition, the solid solution hardening degree of the phases depending on the alloying of the alloy has a significant effect.

Table 3. Parameters of structure and hardness of the VST2K alloy samples after annealing at the different temperatures followed by air cooling

\begin{tabular}{|c|c|c|c|c|c|}
\hline \multirow{2}{*}{$\begin{array}{l}\text { Composition } \\
\text { of the alloy }\end{array}$} & \multirow{2}{*}{$\begin{array}{c}\text { Annealing } \\
\text { temperature, } \\
{ }^{\circ} \mathrm{C} \\
\end{array}$} & \multirow[t]{2}{*}{$\left(\mathrm{Q} \alpha^{\mathrm{I}}\right), \%$} & \multicolumn{2}{|c|}{$\begin{array}{l}\text { Size of the primary } \\
\alpha \text { phase, } \mu \mathrm{m}\end{array}$} & \multirow[t]{2}{*}{ HRC } \\
\hline & & & $a_{\alpha^{I}}$ & $b_{\alpha^{I}}$ & \\
\hline 1 & 940 & 35 & 8 & 2 & 36 \\
\hline 2 & 920 & 31 & 6 & 1.7 & 38.5 \\
\hline 3 & 880 & 30 & 5 & 1.3 & 42 \\
\hline
\end{tabular}

To eliminate the effect of the amount and dispersion degree of the secondary $\alpha$ phase precipitated during cooling to room temperature, the cooling rate was reduced after isothermal holding at selected temperatures.

The studies showed that furnace cooling practically eliminates the secondary $\alpha$ phase formation and contributes to the coarsening of the primary $\alpha$ phase particles; and annealing of the VST2K alloy of compositions 1,2 and 3 at the temperatures of $880{ }^{\circ} \mathrm{C}, 920{ }^{\circ} \mathrm{C}$ and $880^{\circ} \mathrm{C}$, respectively, followed by slow cooling makes it possible to form a structure similar in parameters for all the three compositions (see Table 4 and Fig. 3) represented by particles of the primary $\alpha$ phase with the sizes of 5-9 $\mu \mathrm{m}$ and close in shape to the globular one. The hardness after annealing was about $35 \mathrm{HRC}$ units for the samples of the first and second compositions and 36 HRC units for those of the third composition (Table. 4). The higher value of hardness for the alloy of composition 3 is explained by the formation of a 
finer structure as a result of annealing and a large solid solution hardening due to the greater alloying of the alloy by $\beta$-stabilizers.

Table 4. Parameters of structure and hardness of the VST2K alloy samples after annealing followed by furnace cooling

\begin{tabular}{|c|c|c|c|c|}
\hline $\begin{array}{c}\text { Composition } \\
\text { of the alloy }\end{array}$ & $\begin{array}{c}\mathrm{Ac}_{3}, \\
{ }^{\circ} \mathrm{C}\end{array}$ & $\begin{array}{c}\text { Annealing temperature, } \\
{ }^{\circ} \mathrm{C}\end{array}$ & $\begin{array}{c}a_{\alpha^{I}} / b_{\alpha^{I}}, \\
\mu \mathrm{m}\end{array}$ & HRC \\
\hline \multirow{3}{*}{1} & \multirow{3}{*}{990} & 940 & $12 / 3$ & 32 \\
\cline { 3 - 5 } & & 920 & $15 / 3$ & 32 \\
\cline { 3 - 5 } & 980 & 880 & $9.5 / 5$ & 34.5 \\
\hline 2 & 970 & 920 & $5 / 3$ & 35 \\
\hline 3 & 880 & $5 / 2.5$ & 36 \\
\hline
\end{tabular}

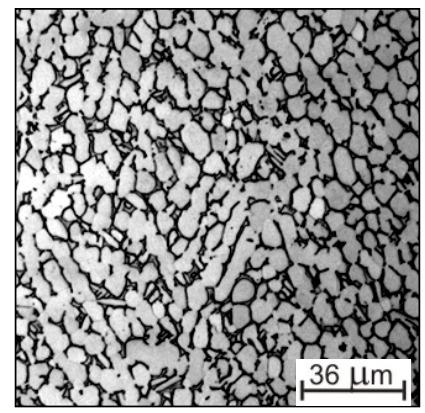

(a)

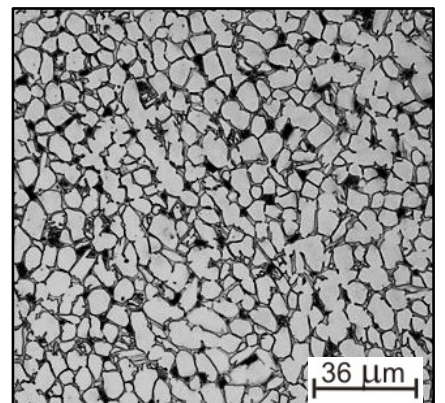

(b)

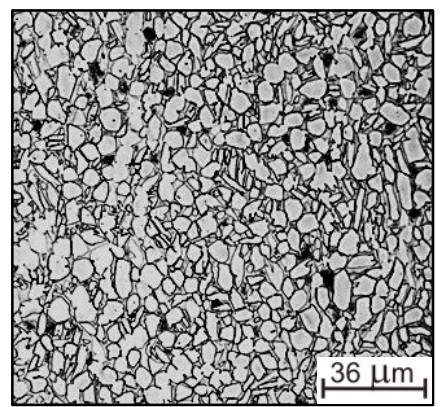

(c)

Fig. 3. Structure of the VST2K alloy with compositions 1 (a), 2 (b) and 3 (c) after annealing at the temperatures of $880^{\circ} \mathrm{C}(\mathrm{a}), 920^{\circ} \mathrm{C}$ (b) and $880^{\circ} \mathrm{C}$ (c) during 1 hour and furnace cooling

\section{Conclusions}

The study of the heating temperature and the cooling rate influence on the number and size of the structural components in the VST2K alloy showed that for the three different alloy compositions air cooling carried out from the temperatures of $940{ }^{\circ} \mathrm{C}$ (composition 1), 920 ${ }^{\circ} \mathrm{C}$ (composition 2) and $880{ }^{\circ} \mathrm{C}$ (composition 3) resulted in the formation of a structure with a close amount of the primary $\alpha$ phase; however, a rather large difference in the hardness of the samples was observed. The heating temperatures and the cooling rate were determined which ensure the formation of a similar structure and approximately the same level of properties for the three melts of the VST2K alloy with different chemical composition. Annealing of the VST2K alloy with compositions 1,2 and 3 at the temperatures of $880{ }^{\circ} \mathrm{C}$, $920{ }^{\circ} \mathrm{C}$, and $880{ }^{\circ} \mathrm{C}$, respectively, followed by slow furnace cooling allows to form structure with a globular morphology of the primary $\alpha$ phase particles being $5-9 \mu \mathrm{m}$ in size and providing hardness of 35-36 HRC units.

Equipment support from the Centre of Collective Use “Aerospace Materials and Technologies" of MAI is gratefully acknowledged.

\section{References}

1. M.Yu. Kollerov, V.S. Spector, S.V. Skvortsova, A.M. Mamonov. D.E. Gusev, G.V. Gurtovaya, Titan. № 2 (48), pp. 42-53 (2015). 
2. Ya.L. Gurevich, Cutting parameters for hard-to-cut materials. Handbook (Mashinostroenie, 1976).

3. P.G. Petruha, Cutting of hard-to-cut materials. Handbook (Mashinostroenie, 1972).

4. V.V. Tetuhin, I.V. Levin, I.Yu. Puzakov, N.Yu. Tarenkova, Patent № RU2425164, IPC C22C14/00, C22C1/02, C22B9/20, Secondary titanium alloy and method for its manufacture, VSMPO-AVISMA (27.07.2011, priority № 2010101764/02, 20.01.2010).

5. A.A. Il'in, B.A. Kolachev, I.S. Pol'kin. Titanium alloys. The composition, structure and properties. Handbook. (VILS-MATI, 2009).

6. G. Lütering, J.C. Williams. Titanium, Engineering materials and processes, Springer, ISBN 3-540-42990-5.

7. N.F. Anoshkin, Metallography of titanium alloys (Metallurgiya, 1980). 